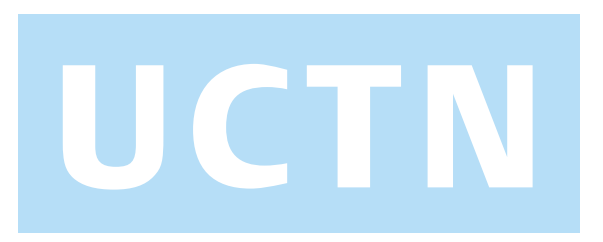

Hemorrhage is the most common complication associated with resection of colorectal polyps. In large polyps specifically, the occurrence either during the procedure or afterwards as an early or late complication can be as high as $24 \%$ overall [1]. To prevent postpolypectomy hemorrhage, we have devised a loop made of standard nylon fishing line which is applied using a polypectomy snare.

To make the loop we used a nylon fishing line of gauge number 0.60 , constructing a knot as illustrated in Fig. 1. The size of the loop depended upon the size of the polyp.

\title{
Hand-Made Loop Applied With Snare to Prevent Postpolypectomy Bleeding
}

After constructing the loop we attached it to the end of a conventional polypectomy snare, which was introduced through the working channel with the device already assembled. The polyp stalk was correctly identified and then ligated with the nylon loop. Polypectomy using a conventional diathermic snare above the nylon loop was then carried out (Fig. 2). In order to close the large loop it is necessary to disconnect the snare from the grip. We recommend the use of a diathermic snare with a high resistance catheter which should be elongated when tightening the loop.
To date there are few studies about the efficacy of ligating the polyp stalk to prevent hemorrhage. When Iishi et al. [2] applied a loop in large polyps, no hemorrhage was observed during or after the procedure, whereas it occurred in $12 \%$ of patients in the control group. Matsushita et al. [3] observed that the loop did not securely bind subpedunculated polyps, or vascular stumps after polypectomy.

The hand-made loop described here has been shown to be practical and efficient in ligating the polyp stalk before polypectomy.
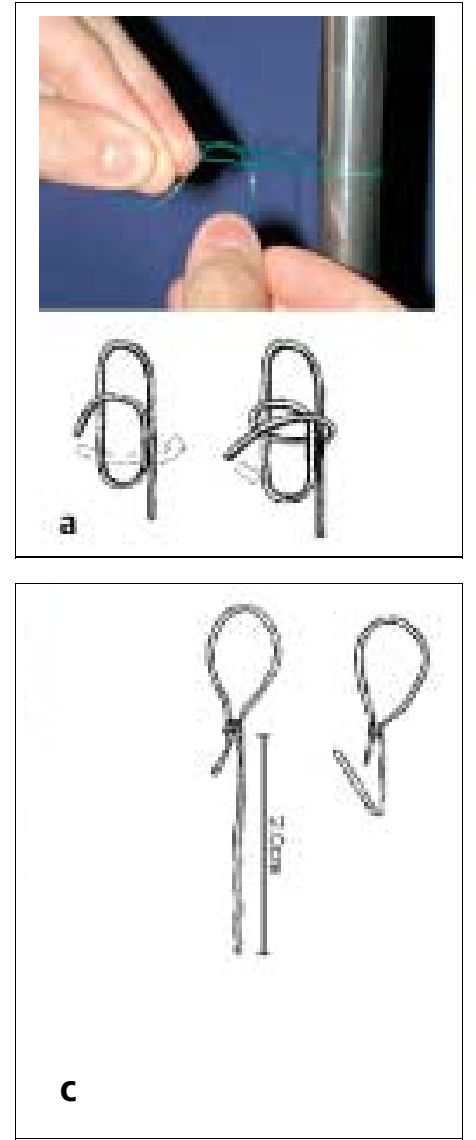

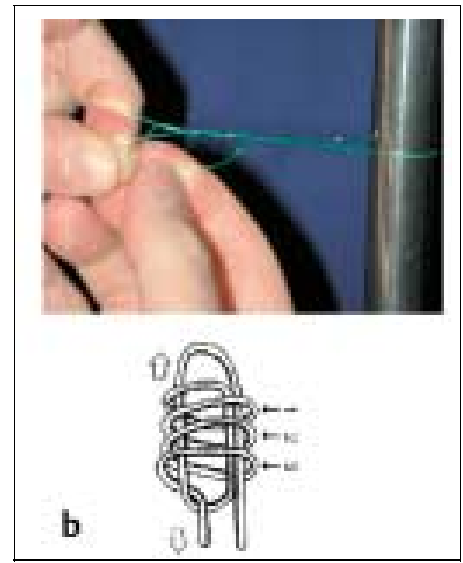

Figure 1 Construction of the loop. a Grasp the two ends of the line, and pass one of the ends around the held sections, as shown. b After the third turn, pass the end of the line inside the loop formed with the first turn. c Cut the ends of the the line, allowing a length of $0.5 \mathrm{~cm}$ for one end and $2.0 \mathrm{~cm}$ for the other, which is then bent round. $\mathbf{d}$ Attach the bent end to the polypectomy snare, anchoring the knot in the tip of the snare. 

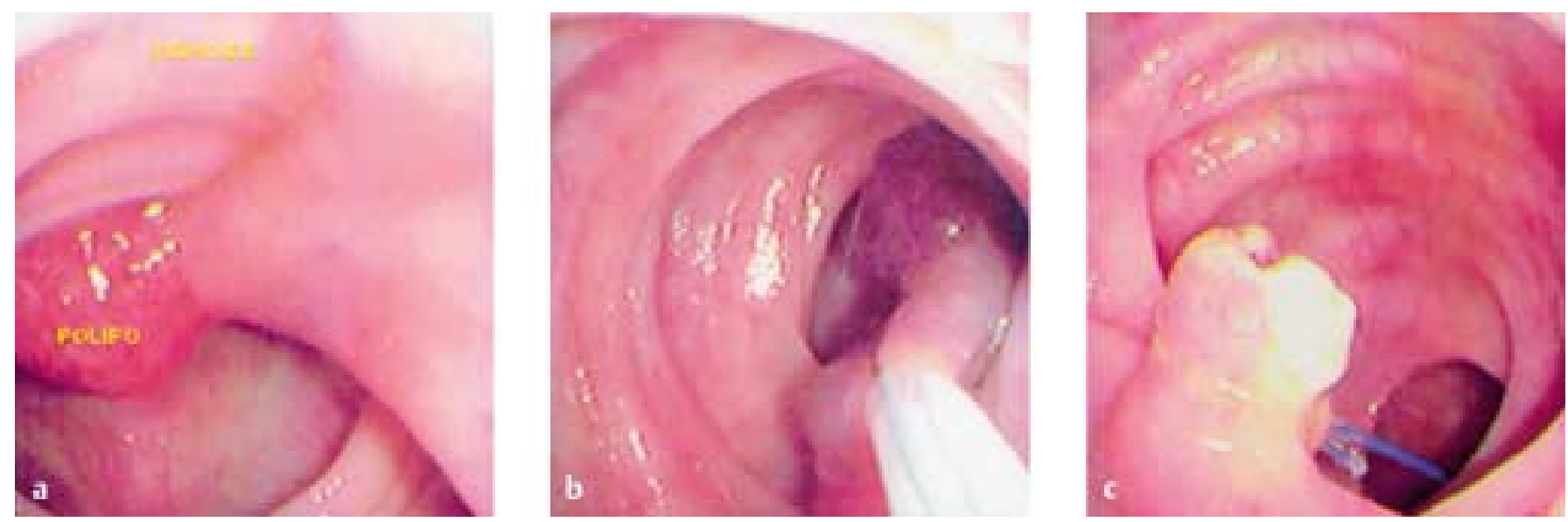

Figure 2 Polyp resection after banding the pedicle using a loop. a Pedunculated polyp. b Ligating the pedicle with the loop. $\mathbf{c}$ Loop securing the pedicle after resection of the polyp.

D. Marques Chaves, S. Matuguma, P. Sakai, S. Penagos, S. Ishioka Endoscopy Service, Hospital das Clínicas da FMUSP, University of São Paulo Medical School, São Paulo, Brazil.

\section{References}

${ }^{1}$ Binmoeller KF, Bohnacker S, Seifert Het al. Endoscopic snare excision of "giant" colorectal polyps. Gastrointest Endosc 1996; 43: $183-188$

${ }^{2}$ Iishi H, Tasuta M, Narahara Het al. Endoscopic resection of large pedunculated coloretal polyps using a detachable snare. Gastrointest Endosc 1996; 44: 594-596

${ }^{3}$ Matsushita M, Hajiro K, Takakuwa Het al. Ineffective use of a detachable snare for colonoscopic polypectomy of large polyps. Gastrointest Endosc 1998; 47: 496-499

\section{Corresponding Author}

\section{Marques Chaves, M.D.}

Rua Montezuma 183

Jd. Das Bandeiras

05436-080 Sao Paulo

Brazil

Fax: + 55-11-36757359

E-mail: dalton.chaves@fleury.com.br 